\title{
Caracterização das espécies utilizadas na arborização urbana em Silveira Martins, $\mathbf{R S}^{(1)}$
}

\author{
FERNANDA ALICE ANTONELLO LONDERO BACKES ${ }^{(2, *)}$, LEONITA BEATRIZ GIRARDI(3), MAURICIO NEUHAUS ${ }^{(3)}$, \\ ROGÉRIO ANTONIO BELLÉ(2), NATALIA TEIXEIRA SCHWAB(3), MARCIA XAVIER PEITER(4)
}

\begin{abstract}
RESUMO
O presente trabalho foi desenvolvido na região da Quarta Colônia, município de Silveira Martins (RS). O objetivo foi fazer um inventário quali-quantitativo das espécies arbóreas, arbustivas e de palmeiras utilizadas na arborização urbana do município. Para isso, foram contabilizados a frequência de ocorrência das espécies, sua origem, estado geral das plantas, aspecto da copa, condição fitossanitária, além da observação da ocorrência de danos à fiação e às calçadas. Foram encontrados 1.126 indivíduos, distribuídos em 75 espécies, sendo as famílias predominantes Bignoniaceae e Fabaceae, e Handroanthus heptaphyllus (Vell.) Mattos a espécie arbórea mais frequente. Quanto aos danos ao patrimônio público, observou-se que $96 \%$ dos indivíduos que compõem a arborização urbana não causaram prejuízos às calçadas e à fiação aérea. Concluiu-se que a arborização de Silveira Martins (RS) se caracteriza por apresentar a maioria de indivíduos nativos do Brasil (58\%), destacando-se as espécies Handroanthus heptaphyllus (Vell.) Mattos, Caesalpinia peltophoroides Benth., Syagrus romanzoffiana (Cham.) Glassman e Handroanthus chrysotrichus (Mart. ex A.DC.) Mattos. Conclui-se que há a necessidade de uma revitalização da vegetação arbórea, arbustiva e de palmeiras, considerando que em Silveira Martins não existe planejamento da distribuição dos indivíduos vegetais no contexto urbano do município.
\end{abstract}

Palavras-chave: inventário, frequência de espécies, qualidade de vida.

\section{ABSTRACT \\ Characterization of species used in urban afforestation in Silveira Martins, RS}

\begin{abstract}
This paper has been developed in the region of Quarta Colônia, city of Silveira Martins (RS). Its objective was to carry out a quali-quantitative inventory of the species employed in the urban afforestation of the city. For that, we have accounted for frequency of occurrence of species, their origin, general plant conditions, aspect of treetop, plant health, besides observing the occurrence of damages to the light wiring and sidewalks. 1.126 individuals were found, distributed in 75 species. The main families were Bignoniaceae and Fabaceae, and Handroanthus heptaphyllus (Vell.) Mattos was the most frequent tree species. Regarding to damages to the public property, we have observed that $96 \%$ of the individuals which compose the urban afforestation did not cause any damage to the sidewalks and light wiring. One of the conclusions is that the afforestation of Silveira Martins (RS) is characterized by presenting most of the individuals native to Brazil (58\%), from which the species Handroanthus heptaphyllus (Vell.) Mattos, Caesalpinia peltophoroides Benth., Syagrus romanzoffiana (Cham.) Glassman and Handroanthus chrysotrichus (Mart. ex A.DC.) Mattos stand out. Another conclusion is that there is a need for revitalization of the tree and shrub vegetation as well as of palm trees, considering that Silveira Martins does not have any planning for the distribution of plant individuals in the urban context.
\end{abstract}

Keywords: inventory, frequency of species, quality life.

\section{INTRODUÇÃO}

A vegetação urbana desempenha importantes funções nas cidades, proporcionando o bem-estar psíquico e psicológico ao homem, a melhoria das qualidades estéticovisuais, sombra para pedestres e veículos, além de amortecer o som e reduzir o impacto da água da chuva, contribuindo assim para a qualidade de vida da população (PIVETTA e SILVA FILHO, 2002).

Com o crescimento exacerbado das cidades, a arborização urbana ficou prejudicada, principalmente em relação ao planejamento, manejo e plantio de árvores, sendo muitas vezes posta em segundo plano pelos órgãos competentes (SILVA et al., 2009). A vegetação no contexto urbano, além de ser responsabilidade do Poder Público, é também considerada um patrimônio dos munícipes, devendo ser conhecida e preservada para as futuras gerações.
Qualitativamente, a arborização de ruas deve apresentar equilíbrio na frequência de distribuição das espécies e compatibilização entre o porte das árvores e o espaço físico disponível para o plantio, fatores esses muitas vezes negligenciados no planejamento urbano (TEIXEIRA, 1999). Alguns autores ressaltam a importância de um planejamento paisagístico adequado ao meio urbano, já que a não observação de certas regras pode ocasionar problemas à rede elétrica e telefônica, à estrutura dos pavimentos e às redes de esgoto (MIRANDA e CARVALHO, 2009; FALEIRO e AMÂNCIO-PEREIRA, 2007). O conhecimento das características do solo e do clima bem como o tamanho das vias e calçadas são informações imprescindíveis que, aliadas ao conhecimento da fenologia das espécies com potencial para uso urbano, servirão de embasamento para o planejamento da arborização.

Nas pequenas cidades em expansão, caso de Silveira Martins, o planejamento urbano torna-se ainda mais

\footnotetext{
${ }^{(1)}$ Recebido em 24/07/2010 e aceito para publicação em 13/07/2011.

${ }^{(2)}$ Professor(a) Doutor(a) do Departamento de Fitotecnia, Universidade Federal de Santa Maria (UFSM), 97105-900, Santa Maria, RS, Brasil. E-mail: fernanda@backes.com.br.*Autor para correspondência.

(3)Mestrando(a) Programa de Pós-graduação em Engenharia Agrícola, UFSM, Santa Maria, RS, Brasil.

${ }^{(4)}$ Professora Doutora do Departamento de Engenharia Agrícola, UFSM, Santa Maria, RS, Brasil.
} 
importante pela necessidade de manutenção do contato do homem com a natureza. DEFANI et al. (2007) consideram que o crescimento urbano e o da população acarretam algumas modificações ambientais, como a redução da cobertura vegetal ocasionada pela pavimentação de calçadas e ruas, o que provoca a impermeabilização dos solos, trazendo consequências negativas para o contexto urbano.

Salienta-se também a utilização da arborização como ferramenta para o fomento do turismo, sendo algumas árvores marcantes na cultura paisagística étnica das diferentes regiões do sul do Brasil, como Platanus acerifolia (Aiton) Willd. para os italianos, Cupressus sempervirens L. para os portugueses, Cunninghamia lanceolata (Lamb.) Hooker f. para os alemães e asiáticos e Melia azedarach L. para o gaúcho. Todas essas espécies apresentam razões culturais para o seu uso, seja produzindo sombra, alimento, utensílios, ou simplesmente embelezando a paisagem (BACKES e IRGANG, 2004).

O município de Silveira Martins é considerado berço da Quarta Colônia, pois, segundo SANTIN e ISAIA (1990), recebeu as primeiras levas de imigrantes italianos, provenientes do norte da Itália, na região central do estado do RS, dando início ao $4^{\circ}$ Núcleo de Imigração Italiana do Estado, juntamente com os outros três primeiros núcleos: Caxias do Sul, Bento Gonçalves e Garibaldi. Por esse motivo, torna-se importante rota turística da Região Central, fazendo-se necessária uma análise da vegetação existente pela importância do planejamento da arborização para o desenvolvimento e melhoria da qualidade ambiental do contexto urbano. Dessa forma, o trabalho teve por objetivo analisar a vegetação arbórea, arbustiva e de palmeiras de Silveira Martins por meio de um inventário florístico, a fim de fornecer subsídios para futuros programas de monitoramento e manejo paisagístico no município.

\section{MATERIAL E MÉTODOS}

Silveira Martins situa-se entre as coordenadas $29^{\circ} 34^{\prime}$ de latitude S e 5339' longitude W, ocupando uma área territorial de $118 \mathrm{~km}^{2}$. Este município está inserido na região da Quarta Colônia, fundada em 1877, a qual representa a quarta área onde foram distribuídas terras para os italianos que imigraram para o Estado. Atualmente, Silveira Martins possui uma densidade demográfica de $20,68 \mathrm{hab} / \mathrm{km}^{2}$, com população de 2.449 habitantes (IBGE, 2010).

O clima de Silveira Martins é classificado como Temperado Mesotérmico e Úmido, do tipo Cfa de Koeppen. A precipitação térmica anual varia em torno de 1.500 a $2.000 \mathrm{~mm}$, podendo ocorrer estiagens, na maioria das vezes, de curta duração, de um ou dois meses. As chuvas são essencialmente frontais, isto é, causadas por passagens de frentes frias (frentes polares), e mais esporadicamente por frentes quentes sobre a região (VIEIRA e ROVANI, 2009).

Segundo VIEIRA e ROVANI(2009), a vegetação natural era constituída pela Floresta Subtropical subcaducifólia. A presença desta vegetação se localiza na atualidade nos locais de relevo mais íngreme. Em locais mais acidentados e pedregosos, abandonados pelos agricultores, ocorre vegetação secundária. Segundo REIS e CAMPAGNER
(2001), além das matas nativas, ocorrem também matas de reflorestamento, com predominância do eucalipto, para atender a exigências legais, ocupando espaços antes desmatados pela lavoura itinerante.

Os tipos de solo que predominam no município de Silveira Martins são: o Litólico, com 60\% localizado nas encostas íngremes dos morros, e o Brunezem avermelhado, em 40\% localizado nos topos do Planalto, em cima da Serra de São Martinho (VIEIRA e ROVANI, 2009).

O levantamento arbóreo, arbustivo e de palmeiras foi realizado por meio de um inventário quali-quantitativo da totalidade da vegetação urbana na cidade de Silveira Martins, no período de fevereiro a março de 2010, totalizando 11 ruas, duas avenidas e a única praça existente, denominada Giuseppe Garibaldi.

Para a identificação das espécies botânicas (nome científico, nome popular, família e origem), foi utilizada literatura especializada (LORENZI, 1998; LORENZI, 2003; GROSE e OLMSTEAD, 2007; FLORA DIGITAL DO RS, 2011), além do auxílio de profissionais do Setor de Botânica da Universidade Federal de Santa Maria (UFSM). Também foram avaliados a quantidade de indivíduos por espécie (frequência) e os parâmetros qualitativos de cada indivíduo segundo metodologia adaptada de FARIA et al. (2007) e PAIVA (2009).

Os parâmetros qualitativos avaliados foram: Estado geral das plantas: ótimo (árvore vigorosa e sadia, nenhuma necessidade de manutenção), bom (árvore sadia, com pouca necessidade de manutenção), regular (médias condições de vigor e saúde, necessita de reparos ou poda) e péssimo (avançado e irreversível declínio, descaracterizando sua arquitetura ou desequilibrando o vegetal); Aspecto da copa: normal (arquitetura normal da espécie), medianamente deformada (com copa levemente diferente da normal para a espécie, apresentando sinais leves de poda e sem danos estruturais) e deformada (copa com arquitetura diferente do padrão da espécie ou exibindo sinais de poda drástica); Condição fitossanitária: com injúria (apresenta ataque por insetos, doenças ou injúria mecânica) e sem injúria (ausência de sinais aparentes de ataque de insetos, doenças ou injúrias mecânicas); Ocorrência de danos ao patrimônio público: com danos à fiação, com danos à calçada e sem danos ao patrimônio público.

\section{RESULTADOS E DISCUSSÃO}

O levantamento das espécies arbóreas, arbustivas e de palmeiras das vias públicas de Silveira Martins totalizou 1.126 indivíduos, sendo $65 \%$ arbóreos, $23,45 \%$ arbustivos e $11,55 \%$ palmeiras, pertencentes a 75 espécies botânicas e distribuídos em 33 famílias (Tabelas 1 e 2), além de 35 indivíduos mortos, sendo estes de difícil identificação por estarem em fase de muda.

Verificou-se recente introdução de mudas de diferentes espécies botânicas, parte realizada por moradores locais e parte por um convênio entre a Prefeitura Municipal e a Empresa de Energia Usina Nova Palma em diversas ruas de Silveira Martins, feita sem critério quanto à distribuição espacial dos indivíduos, não sendo considerada a vegetação existente no entorno. Entretanto, algumas dessas espécies, como Caesalpinia peltophoroides 
Benth. e Handroanthus heptaphyllus (Vell.) Mattos, podem ser utilizadas no meio urbano, desde que sejam consideradas algumas características da espécie como a altura, a estrutura da copa e o sistema radicular. BIONDI e ALTHAUS (2005) recomendam o uso de uma mesma espécie pelo menos em uma mesma quadra, para não diluir o efeito estético dos atributos das árvores, principalmente a floração. Destacam ainda que uma mesma via pública poderá ser arborizada por diferentes espécies, já que uma rua geralmente é formada por inúmeras quadras. SANTOS e TEIXEIRA (2001) consideram outras possibilidades de combinações na distribuição dos elementos vegetais no contexto urbano, como, por exemplo, espécies diferentes de cada lado do passeio; espécies iguais em ambos os lados e diferentes no canteiro central; duas espécies com distribuição intercalada entre quadras. Em Silveira Martins, foi observado que poucas vias públicas apresentam distribuição ordenada conforme o recomendado, como observado no canteiro central das avenidas Antônio A. Vedoin, com Handroanthus heptaphyllus (Vell.) Mattos e Handroanthus chrysotrichus (Mart. ex A.DC.) Mattos e Osvaldo Zambonato com a presença de Syagrus romanzoffiana (Cham.) Glassman. Em ambas as avenidas, os lados do passeio não apresentavam distribuição ordenada com indivíduos jovens, implantados recentemente.

Analisando os resultados, verificou-se que Silveira Martins é uma cidade mediamente diversificada quanto ao número de espécies (75). ANDREATTA et al. (2011) encontraram 95 espécies somente nas principais avenidas de Santa Maria (RS), considerando o índice de diversidade bom $(12,03)$.

As famílias que apresentaram maior ocorrência de indivíduos arbóreos foram Bignoniaceae e Fabaceae (Tabela 1), com $43 \%$ e $31 \%$, respectivamente. De modo geral, a família Bignoniaceae, representada por Jacaranda mimosifolia D. Don. e diferentes espécies de Handroanthus, apresenta flores bastante vistosas e vivamente coloridas, o que lhe atribui valor ornamental, além de porte compatível com o ambiente urbano (praças, canteiros de ruas e avenidas, entre outros), contribuindo positivamente para a arborização de uma cidade.

Observando-se a origem das espécies utilizadas na arborização de Silveira Martins, verificou-se que a maioria dos exemplares são de essências nativas brasileiras (58\%), sendo as de maior representatividade pertencentes às espécies Handroanthus heptaphyllus (Vell.) Mattos (13\%), Caesalpinia peltophoroides Benth (12\%), Syagrus romanzoffiana (Cham.) Glassman (10\%) e Handroanthus chrysotrichus (Mart. ex A.DC.) Mattos (6\%). Esses dados divergem da situação da maioria dos municípios brasileiros (PAIVA, 2009) e também dos encontrados por SOUZA et al. (2009) em Santiago (RS) e ANDREATTA et al. (2011) em avenidas de Santa Maria (RS), em que 73\% e $65,89 \%$, respectivamente, da arborização é composta por espécimes exóticos. A predominância de material vegetal nativo no contexto urbano é considerada positiva, já que permite uma maior sustentabilidade ecológica do ambiente (PAIVA, 2009).

Entre as espécies arbustivas, destacam-se a Thuja orientalis L. (7\%), Ligustrum sinensis Lour. (4,17\%) e
Brunfelsia uniflora (Pohl) D. Don (3,81\%) em relação ao total de indivíduos amostrados no levantamento florístico (Tabela 2).

Salienta-se, ainda, que nenhuma das espécies encontradas no município apresenta frequência superior a $15 \%$, considerada por MILANO e DALCIN (2000) o limite máximo para um bom planejamento urbano.

A maioria dos indivíduos analisados, 55.06\%, apresenta bom estado de conservação (Figura 1). Embora o resultado encontrado nesta análise não represente um cenário negativo, a condição ideal para o município seria o enquadramento da maioria dos indivíduos na categoria ótimo. Entretanto, torna-se onerosa a manutenção dos indivíduos nesta categoria, já que engloba condições ideais de estrutura de copa, fitossanidade e desenvolvimento de raízes. Salienta-se que, muitas vezes, as espécies são danificadas pelos transeuntes, e sua manutenção, em geral, realizada por pessoas sem conhecimento técnico.

Verifica-se que $74,16 \%$ dos indivíduos analisados no contexto urbano de Silveira Martins se encontram sem ataque de pragas, doenças ou danos mecânicos, enquanto 25,84\% apresentam algum estado de injúria (Figura 1), frequência considerada bastante alta por RODOLFO JÚNIOR et al. (2008).

Quanto à estrutura da copa (Figura 2), observa-se que mais de $50 \%$ dos indivíduos estão na categoria normal, ou seja, sem deformações significativas causadas por podas inadequadas ou demais injúrias, e aproximadamente 18\% apresentam deformações severas, muitas vezes devidas ao fato de terem sido implantadas em local inadequado, obrigando a realização de podas de compatibilização com o local. Para estes indivíduos, é recomendada a substituição por espécies adequadas ao ambiente urbano.

Verifica-se que a grande maioria dos indivíduos (96\%) que compõem a arborização urbana de Silveira Martins não causa prejuízos ao patrimônio público. Destaca-se que a atual implantação de indivíduos jovens nas vias públicas do município contribui sobremaneira para o baixo percentual de danos às calçadas ( $1 \%$ ) e à fiação aérea (3\%). No entanto, algumas das espécies implantadas, tais como Caesalpinia peltophoroides Benth., Handroanthus heptaphyllus (Vell.) Mattos, Inga marginata Willd. e Schinnus terebinthifolius Raddi., ainda não expressaram todo o seu potencial de desenvolvimento e, futuramente, poderão causar danos ao patrimônio se não forem usadas adequadamente para compor a paisagem urbana em local adequado. Salientase ainda que Silveira Martins não mantém uma identidade étnico-cultural preservada em sua vegetação no contexto urbano, destacando-se apenas os Cupressus sempervirens presentes na Praça Central pela idade avançada, os quais provavelmente foram implantados no início da colonização italiana.

\section{CONCLUSÃO}

A arborização de Silveira Martins caracteriza-se por apresentar a maioria de indivíduos nativos da flora brasileira, destacando-se Handroanthus heptaphyllus (Vell.) Mattos, Caesalpinia peltophoroides, Syagrus romanzoffiana (Cham.) Glassman e Handroanthus chrysotrichus (Mart. ex A.DC.). 


\section{REFERÊNCIAS}

ANDREATTA, T.R.; BACKES, F.A.A.L.; BELLÉ, R.A.; NEUHAUS, M; GIRARDI,L.B.; SCHWAB, N.T.; BRANDÃO, B. S. Análise da arborização no contexto urbano de avenidas de Santa Maria, RS. Revista da Sociedade Brasileira de Arborização Urbana, Piracicaba, v.6, n.1, p.36-50, 2011.

BACKES, P.; IRGANG, B. Árvores cultivadas no sul do Brasil - Guia de Identificação e interesse paisagístico das principais espécies exóticas. Paisagem do Sul: Porto Alegre, v. 1, 2004. 204 p.

BIONDI, D.; ALTHAUS, M. Árvores de rua de Curitiba: Cultivo e Manejo. FUPEF: Curitiba, 2005, 177 p.

DEFANI, M. A.; CARDOSO, C. A.; CROSCATO, G.; OLIVEIRA, J.; ARAÚJO, J.; MARTINES, S.; GONÇALVES, S.; CAVALCANTI, F. M. Levantamento Parcial da vegetação Urbana no município de Goioerê-PR. Revista Arquivos do Mudi, Maringá, v.11, n.1, p. 28-33, 2007.

FALEIRO, W.; AMÂNCIO-PEREIRA，F. Arborização viária do Campus Umuarama da Universidade Federal de Uberlândia, MG. Revista Científica Eletrônica de Engenharia Florestal, Garça, ano VI, n. 10, 2007.

FARIA, J. L. G.; MONTEIRO, E. A.; FISCH, S. T. V. Arborização de vias públicas do município de JacareíSP. Revista da Sociedade Brasileira de Arborização Urbana, Piracicaba, v.2, n.4, p. 20-33, 2007.

FLORA DIGITAL DO RS. Disponível em: <http://www6. ufrgs.br/fitoecologia/florars/>. Acesso em: 31 de maio de 2011.

GROSE, S. O.; OLMSTEAD, R. G. Taxonomic Revisions in the Polyphyletic Genus Tabebuia s. 1. (Bignoniaceae). Systematic Botany, Laramaie, v. 32, n.3, p 660-670, 2007.

IBGE. Instituto Brasileiro de Geografia e Estatística. Disponível em: $\quad<\mathrm{http} / / / \mathrm{www}$. ibge.gov.br/home/>. Acessado em: 20 de maio de 2010.

LORENZI, H. Árvores brasileiras: Manual de identificação e cultivo de plantas arbóreas do Brasil. v. 1. São Paulo, 1998. 352p.

LORENZI, H. Árvores exóticas no Brasil. São Paulo, 2003. 368p.

MILANO, M.; DALCIN, E. Arborização de vias públicas. Rio de Janeiro: LIGHT, 2000. 226p.

MIRANDA, T. O.; CARVALHO, S. M. Levantamento Quantitativo e Qualitativo de indivíduos arbóreos presentes nas vias do bairro da ronda em Ponta Grossa-PR. Revista da Sociedade Brasileira de Arborização Urbana, Piracicaba, v.4, n.3, p. 143-157, 2009.

PAIVA, A. V. Aspectos da arborização urbana do centro de Cosmópolis-SP. Revista da Sociedade Brasileira de Arborização Urbana, Piracicaba, v.4, n.4, p. 17-31, 2009.

PIVETTA, K. F. L.; SILVA FILHO, D. F. Arborização urbana. Boletim Acadêmico - Série Arborização Urbana. Jaboticabal: UNESP / FCAV / FUNEP, 2002, 69 p.

REIS, J. T.; CAMPAGNER, M. A. A urbanização de Silveira Martins - Rio grande do Sul - Estudo de caso. Anais... 8 Encuentro de Geografos de America Latina, Santiago de Chile. 2001. p. 464. Disponível em:<http:// observatoriogeograficoamericalatina.org. $\mathrm{mx} / \mathrm{egal} / \mathrm{d}$ Geografiasocioeconomica/Geografiaurbana/28.pdf $>$. Acesso em: 15 de jun. 2011.

RODOLFO JÚNIOR, F.; MELO, R. R.; CUNHA, T.; STANGERLIN, D. M. Análise da Arborização urbana em bairro da cidade de Pombal no Estado da Paraíba. Revista da Sociedade Brasileira de Arborização Urbana, Piracicaba, v.3, n.4, p. 3-19, 2008.

SANTIN, S.; ISAIA, A. Silveira Martins - Patrimônio histórico-cultural. Porto Alegre: EST, 1990. 96p.

SANTOS, N. R. Z.; TEIXEIRA, I. F. Arborização de vias públicas: Ambiente $\mathrm{x}$ Vegetação. Instituto Souza Cruz: Santa Cruz do Sul, 2001. 135p.

SILVA, L.F. da.; VOLPE-FILIK, A.; LIMA, A.M.L.P.; SILVA FILHO, D.F. da. Análise da arborização viária em dois bairros de Americana/SP. Revista Brasileira de Horticultura Ornamental, Campinas, v.14, n.2, p.147158, 2009.

SOUZA, A. R. C.; FERRAZ, R. C.; SOUZA, G. R. C.; VOLK, A. M. S. B.; ROBAINA, A. D.; PEITER, M. X. Estudo da diversidade da flora utilizada na arborização urbana em um fragmento da cidade de Santiago, Rio Grande do Sul. Anais do II Simpósio de Biodiversidade: "Biodiversidade, Ensino e Evolução". UFSM: Santa Maria. 2009.

TEIXEIRA, I. F. Análise qualitativa da arborização de ruas do conjunto habitacional Tancredo Neves, Santa Maria - RS. Ciência Florestal, Santa Maria, v. 9, n. 2, p. 9-21, 1999.

VIERA, E.G.; ROVANI F.F.M. uso da terra em Silveira Martins: uma nova perspectiva ou possibilidade por meio das geotecnologias. Anais... Encuentro de Geógrafos de América Latina. Montevideo Uruguay. 2009. Disponível em: $<: / /$ egal2009. easyplanners.info/buscar.php?id_tl=3347\#> . Acesso em: 30 de maio 2011. 
Tabela 1. Espécies arbóreas encontradas em Silveira Martins, RS. Santa Maria, 2010

Table 1. Tree species found in Silveira Martins, RS. Santa Maria, 2010

\begin{tabular}{|c|c|c|c|c|}
\hline $\begin{array}{l}\text { Nome científico } \\
\text { Scientific name }\end{array}$ & $\begin{array}{l}\text { Família } \\
\text { Family }\end{array}$ & $\begin{array}{l}\text { Origem } \\
\text { Origin }\end{array}$ & $\mathrm{N}^{\mathrm{O}}$ & $\begin{array}{l}\text { Frequência }(\%) \\
\text { Frequency }(\%)\end{array}$ \\
\hline Handroanthus heptaphyllus (Vell.) Mattos & Bignoniaceae & $\mathrm{N}$ & 141 & 19,26 \\
\hline Caesalpinia peltophoroides Benth & Fabaceae & $\mathrm{N}$ & 131 & 17,90 \\
\hline $\begin{array}{l}\text { Handroanthus chrysotrichus (Mart. ex A.DC.) } \\
\text { Mattos }\end{array}$ & Bignoniaceae & $\mathrm{E}$ & 72 & 9,84 \\
\hline Jacaranda mimosifolia D. Don. & Bignoniaceae & $\mathrm{E}$ & 68 & 9,29 \\
\hline Lagerstroemia indica $\mathrm{L}$. & Lythraceae & $\mathrm{E}$ & 50 & 6,83 \\
\hline Tipuana tipu (Benth.) Kuntze & Fabaceae & $\mathrm{E}$ & 43 & 5,87 \\
\hline Senna macranthera (Collad.) Irwin et Barn. & Fabaceae & $\mathrm{N}$ & 24 & 3,28 \\
\hline Cordia americana (L.) Gottshling \& J.E.Mill. & Boraginaceae & $\mathrm{N}$ & 16 & 2,19 \\
\hline Tabebuia sp. & Bignoniaceae & $\mathrm{N}$ & 15 & 2,05 \\
\hline Ligustrum lucidum W.T. Aiton & Oleaceae & $\mathrm{E}$ & 13 & 1,78 \\
\hline Schinnus terebinthifolius Raddi. & Anacardiaceae & $\mathrm{N}$ & 12 & 1,64 \\
\hline Cybistax antisyphilitica (Mart.) Mart. & Bignoniaceae & $\mathrm{N}$ & 11 & 1,50 \\
\hline Syzygium cuminni (L.) Skeels & Myrtaceae & $\mathrm{E}$ & 10 & 1,37 \\
\hline Pterocaria $\mathrm{x}$ rehderiana C.K. Schneider & Juglandaceae & $\mathrm{E}$ & 9 & 1,23 \\
\hline Cassia leptophylla Vogel & Fabaceae & $\mathrm{N}$ & 8 & 1,09 \\
\hline Cupressus lusitanica Mill. & Cupressaceae & $\mathrm{E}$ & 8 & 1,09 \\
\hline Inga marginata Willd. & Fabaceae & $\mathrm{N}$ & 8 & 1,09 \\
\hline Parapiptadenia rigida (Benth.) Brenan & Fabaceae & $\mathrm{N}$ & 8 & 1,09 \\
\hline Psidium cattleianum Sabine & Myrtaceae & $\mathrm{N}$ & 7 & 0,96 \\
\hline Psidium guajava L. & Myrtaceae & $\mathrm{N}$ & 7 & 0,96 \\
\hline Citrus $x$ sinensis (L.) Osbeck & Rutaceae & $\mathrm{E}$ & 6 & 0,82 \\
\hline Eugenia uniflora L. & Myrtaceae & $\mathrm{N}$ & 6 & 0,82 \\
\hline Platanus acerifolia (Aiton) Willd. & Platanaceae & $\mathrm{E}$ & 5 & 0,68 \\
\hline Cedrela fissilis Vell. & Meliaceae & $\mathrm{N}$ & 4 & 0,55 \\
\hline Melia azedarach L. & Meliaceae & $\mathrm{E}$ & 4 & 0,55 \\
\hline Campomanesia xanthocarpa O.Berg & Myrtaceae & $\mathrm{N}$ & 3 & 0,41 \\
\hline Eriobotrya japonica (Thunb.) Lindl. & Rosaceae & $\mathrm{E}$ & 3 & 0,41 \\
\hline $\begin{array}{c}\text { Handroanthus pulcherrimus (Sandwith) } \\
\text { S.O.Grose }\end{array}$ & Bignoniaceae & $\mathrm{N}$ & 3 & 0,41 \\
\hline Ceiba speciosa (A. St.-Hil.) Ravenna & Malvaceae & $\mathrm{N}$ & 2 & 0,27 \\
\hline Cupressus sempervirens L. & Cupressaceae & $\mathrm{E}$ & 2 & 0,27 \\
\hline Enterolobium contortisiliquum (Vell.) Morong & Fabaceae & $\mathrm{N}$ & 2 & 0,27 \\
\hline Ficus sp. & Moraceae & $\mathrm{E}$ & 2 & 0,27 \\
\hline Grevillea robusta A. Cunn. ex. R. Br. & Proteaceae & $\mathrm{E}$ & 2 & 0,27 \\
\hline
\end{tabular}




\begin{tabular}{|c|c|c|c|c|}
\hline Hovenia dulcis Thunb & Rhamnaceae & $\mathrm{E}$ & 2 & 0,27 \\
\hline Jacaranda micrantha Cham. & Bignoniaceae & $\mathrm{N}$ & 2 & 0,27 \\
\hline Morus nigra L. & Moraceae & $\mathrm{N}$ & 2 & 0,27 \\
\hline Ocotea puberula (Reich.) Nees & Lauraceae & $\mathrm{N}$ & 2 & 0,27 \\
\hline Araucaria columnaris (Forst.) Hook & Araucariaceae & $\mathrm{E}$ & 1 & 0,14 \\
\hline Bauhinia variegata $\mathrm{L}$. & Fabaceae & $\mathrm{E}$ & 1 & 0,14 \\
\hline Caesalpinia ferrea Mart. ex Tul. var. ferrea & Fabaceae & $\mathrm{N}$ & 1 & 0,14 \\
\hline Cassia fistula L. & Fabaceae & $\mathrm{E}$ & 1 & 0,14 \\
\hline Chryptomeria japonica var. 'Elegans' & Taxodiaceae & $\mathrm{E}$ & 1 & 0,14 \\
\hline Cinnamomum zeylanicum Nees & Lauraceae & $\mathrm{E}$ & 1 & 0,14 \\
\hline Citrus reticulata Blanco & Rutaceae & $\mathrm{E}$ & 1 & 0,14 \\
\hline Cupressus sempervirens L. var. 'Stricta' Aiton & Cupressaceae & $\mathrm{E}$ & 1 & 0,14 \\
\hline Handroanthus albus (Cham.) Mattos & Bignoniaceae & $\mathrm{N}$ & 1 & 0,14 \\
\hline $\begin{array}{l}\text { Handroanthus impetiginosus (Mart. ex DC.) } \\
\text { Mattos }\end{array}$ & Bignoniaceae & $\mathrm{N}$ & 1 & 0,14 \\
\hline Inga vera Willd. & Fabaceae & $\mathrm{N}$ & 1 & 0,14 \\
\hline Laurus nobilis L. & Lauraceae & $\mathrm{E}$ & 1 & 0,14 \\
\hline Leucaena leucocephala (Lam.) de Wit & Fabaceae & $\mathrm{N}$ & 1 & 0,14 \\
\hline Magnolia grandiflora L. & Magnoliaceae & $\mathrm{E}$ & 1 & 0,14 \\
\hline Persea americana Mill. & Lauraceae & $\mathrm{E}$ & 1 & 0,14 \\
\hline Prunus persica (L.) Batsch & Rosaceae & $\mathrm{E}$ & 1 & 0,14 \\
\hline Pinus sp. & Pinaceae & $\mathrm{E}$ & 1 & 0,14 \\
\hline Total & & & 732 & 100 \\
\hline
\end{tabular}

Origem das espécies para o Brasil: espécies nativas (N); espécies exóticas (E).

Número total de indivíduos $\left(\mathrm{N}^{\circ}\right)$. 
Tabela 2. Descrição das espécies de palmeiras e arbustivas encontradas em Silveira Martins, RS. Santa Maria, 2010 Table 2. Description of the species of palm trees and shrubs found in Silveira Martins, RS. Santa Maria, 2010

\begin{tabular}{|c|c|c|c|c|}
\hline $\begin{array}{l}\text { Nome científico } \\
\text { Scientific name }\end{array}$ & $\begin{array}{l}\text { Família } \\
\text { Family }\end{array}$ & $\begin{array}{l}\text { Origem } \\
\text { Origin }\end{array}$ & $\mathrm{N}^{\mathrm{O}}$ & $\begin{array}{l}\text { Frequência }(\%) \\
\text { Frequency }(\%)\end{array}$ \\
\hline Syagrus romanzoffiana (Cham.) Glassman** & Palmae & $\mathrm{N}$ & 117 & 29,70 \\
\hline Thuja orientalis L.* & Cupressaceae & $\mathrm{E}$ & 75 & 19,04 \\
\hline Ligustrum sinensi Lour.* & Oleaceae & $\mathrm{E}$ & 47 & 11,93 \\
\hline Brunfelsia uniflora (Pohl) D. Don* & Solanaceae & $\mathrm{N}$ & 43 & 10,91 \\
\hline Hibiscus rosa-sinensis L.* & Malvaceae & $\mathrm{E}$ & 33 & 8,38 \\
\hline Duranta erecta var. 'Gold Mound'* & Verbenaceae & $\mathrm{E}$ & 26 & 6,60 \\
\hline $\begin{array}{c}\text { Archontophoenix cunninghamiana } \\
\text { H. Wendl.\& Drude** }\end{array}$ & Arecaceae & $\mathrm{E}$ & 10 & 2,54 \\
\hline Cordyline terminalis (L.) Kunth* & Laxmanniaceae & $\mathrm{E}$ & 8 & 2,03 \\
\hline Jasminum mesnyi Hance* & Oleaceae & $\mathrm{E}$ & 8 & 2,03 \\
\hline Agave americana L.* & Agavaceae & $\mathrm{E}$ & 4 & 1,02 \\
\hline Calliandra brevipes Benth.* & Fabaceae & $\mathrm{N}$ & 4 & 1,02 \\
\hline Nerium oleander L.* & Apocinaceae & $\mathrm{E}$ & 4 & 1,02 \\
\hline Tibouchina mutabilis Cogn. var. 'Nana'* & Melastomataceae & $\mathrm{E}$ & 4 & 1,02 \\
\hline Thunbergia grandiflora Roxb.* & Acanthaceae & $\mathrm{E}$ & 4 & 1,02 \\
\hline Furcraea foetida (L.) Haw.* & Agavaceae & $\mathrm{N}$ & 2 & 0,51 \\
\hline Yucca guatemalensis Regel.* & Agavaceae & $\mathrm{E}$ & 2 & 0,51 \\
\hline Butia eriospatha (Mart. ex Drude) Becc.** & Arecaceae & $\mathrm{N}$ & 1 & 0,25 \\
\hline $\begin{array}{c}\text { Livistonia chinensis (N. J. Jacquin) R. } \\
\text { Brown ex Mart.** }\end{array}$ & Arecaceae & $\mathrm{E}$ & 1 & 0,25 \\
\hline Phoenix roebelenii O Brien** & Arecaceae & $\mathrm{E}$ & 1 & 0,25 \\
\hline Total & & & 394 & 100 \\
\hline
\end{tabular}

Origem das espécies: espécies nativas $(\mathrm{N})$; espécies exóticas $(\mathrm{E})$.

Número total de indivíduos $\left(\mathrm{N}^{\circ}\right)$.

* Espécie arbustiva.

** Palmeira. 


\section{Estado Geral}

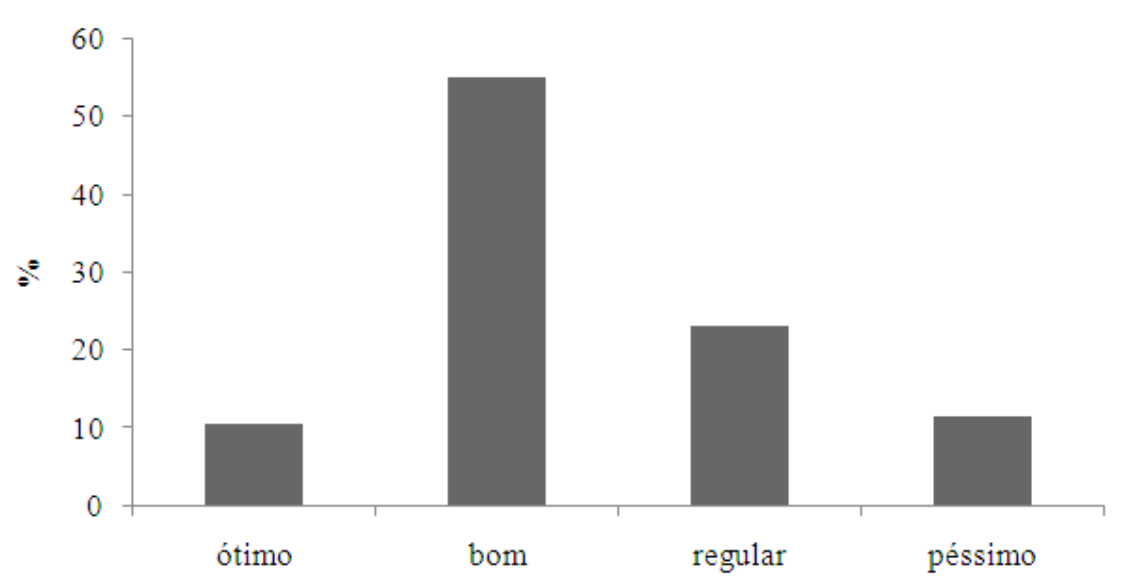

Fitossanid ade

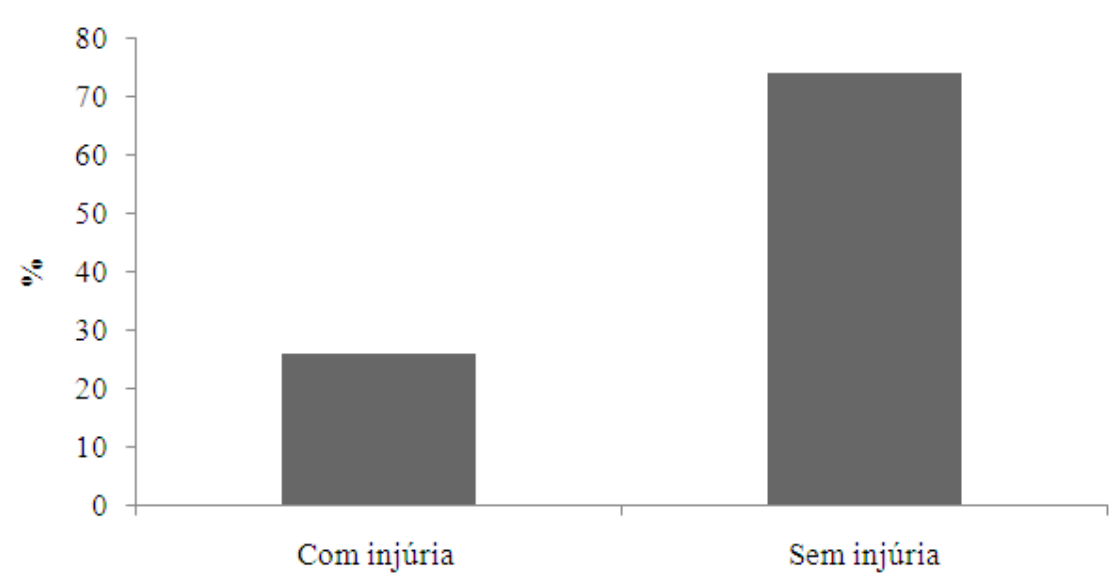

Figura 1. Estado geral e condição fitossanitária dos indivíduos arbóreos e arbustivos utilizados na arborização urbana de Silveira Martins, RS. Santa Maria, 2010.

Figure 1. General state and plant health of the individual trees and shrubs used in urban forestry of Silveira Martins, RS. Santa Maria, 2010.

\section{Copa}

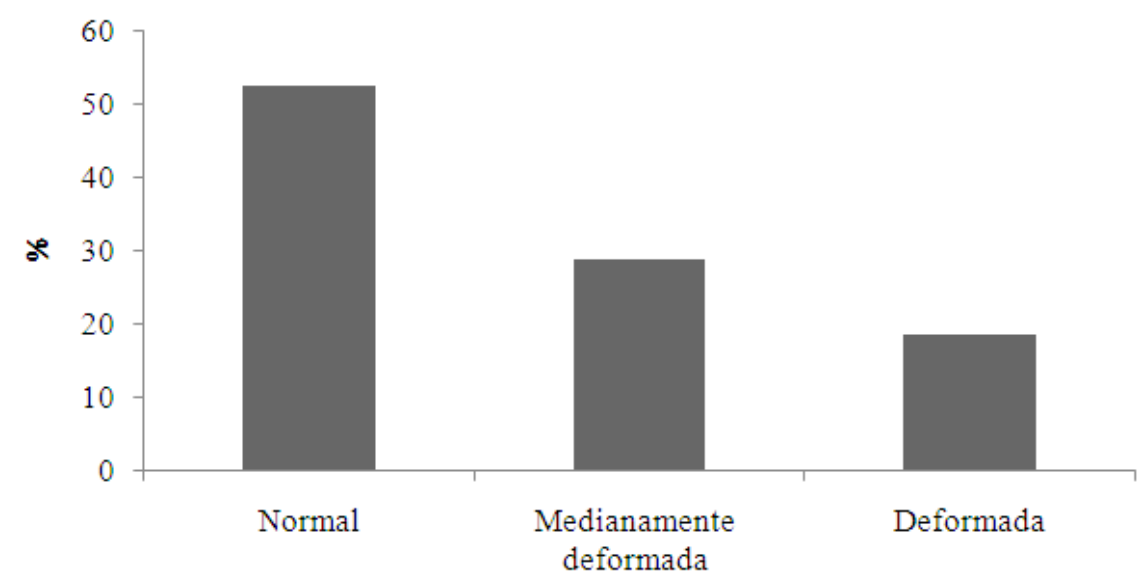

Figura 2. Aspecto da copa de árvores e arbustos utilizados na arborização urbana de Silveira Martins, RS. Santa Maria, 2010.

Figure 2. Aspect of the treetops and shrubs used in the urban forestry of Silveira Martins, RS. Santa Maria, 2010. 